\title{
Relationship between Death Site and Education Degree of Deaths from Bone-Related Diseases in Inner Mongolia
}

\author{
Lifu Chen ${ }^{1,2 \#, ~ R i n a ~ S u}{ }^{1 \#, ~ F e n g q i n g ~ L i 1 \#, ~ Z e y u ~ L u}{ }^{1}$, Meijuan Yan${ }^{1}$, Guanghua Chi' ${ }^{1}$, Chengyi Zhang1, \\ Hongbo Yang1, Kaipeng Wen'1, Zimeng Li1, Dejun Sun ${ }^{3 *}$, Juan Sun ${ }^{*}$
}

${ }^{1}$ Inner Mongolia Honder College of Arts and Sciences, Hohhot, China

${ }^{2}$ Tong Liao City Hospital, Tongliao, China

${ }^{3}$ Inner Mongolia People's Hospital, Hohhot, China

Email: *dejunsun123456@163.com, *sj6840@163.com

How to cite this paper: Chen, L. F., Su, R. N., Li, F. Q., Lu, Z. Y., Yan, M. J., Chi, G. H., Zhang, C. Y., Yang, H. B., Wen, K. P., Li, Z. M., Sun, D. J., \& Sun, J. (2021). Relationship between Death Site and Education Degree of Deaths from Bone-Related Diseases in Inner Mongolia. Advances in Applied Sociology, 11, 585-594.

https://doi.org/10.4236/aasoci.2021.1111050

Received: November 2, 2021

Accepted: November 27, 2021

Published: November 30, 2021

Copyright $\odot 2021$ by author(s) and Scientific Research Publishing Inc. This work is licensed under the Creative Commons Attribution International License (CC BY 4.0).

http://creativecommons.org/licenses/by/4.0/

\begin{abstract}
Objective: To analyze the relationship between education degree and death site of individuals with bone-related diseases in Inner Mongolia. Methods: Using data from death monitoring points in Inner Mongolia from 2008 to 2015, bone-related disease deaths were identified based on the International Classification of Diseases Criteria. Crude mortality, as well as gender-, age-, region-specific mortality and age-specific growth mortality resulting from bone diseases, were calculated. The proportion and chi-square test were carried out. Results: The average bone-related disease mortality rate in Inner Mongolia during the study period was 1.59 per 100,000 individuals, which could be broken down into 1.95 per 100,000 males and 1.20 per 100,000 females. Among bonerelated disease deaths, $68.61 \%$ of afflicted individuals died at home while the remainder mainly died on the way to hospitals and other health institutions. In the classification of bone disease death site, $66.89 \%$ of primary bone cancer died at home. When evaluated by education degree, more people with low education degree died at home (78.03\%) compared to in medical institutions $(21.97 \%)$. High education degree accounted for $50 \%$ of both died at home and in medical-related institutions. Conclusion: For people in Inner Mongolia who die of bone-related diseases, the primary cause of which is bone cancer. Among these individuals, most chose to die at home instead of in medical institutions. Besides education degree, factors such as age, gender, and the region also affected the distribution of death sites.
\end{abstract}




\section{Keywords}

Deaths from Bone-Related Diseases, Education Degree, Death Site

\section{Introduction}

Death monitoring is a key basis for formulating social and economic development plans, evaluating the health level of residents, and optimizing the allocation of health resources (China Disease Control and Health Publish, 2005; Guowei Planning Publish, 2013). Almost all socio-demographic variables, including gender, education degree, urbanization level, marital status, age, and the country of birth, are correlated with where a person with a terminal disease dies (i.e., at home or in a medical institution) (Cabaero-Martínez et al., 2019). There are many factors influencing where people choose to die, including age, marital status, education degree, occupation, and the type of terminal disease (Han et al., 2015). For example, in China, the people without spouses are more likely to die outside the hospital ward (Han et al., 2015), while people with lower education degree, influenced by Chinese traditional culture, are more likely to die at home (Liao et al., 2019; Li et al., 2012). In China, the proportion of hospital deaths is less than $20 \%$, about $1 / 3$ of those in the western countries (Jiang et al., 2020). Data from two hospitals in Wuhan showed that patients with advanced cancer were more likely to die at home, accounting for $79.61 \%$, and $20.39 \%$ in other death sites (Liao et al., 2019). The distribution of death sites has its imbalance. For example, in Min Hang District of Shanghai, more residents died in the medical wards than at home (40\% and $20 \%$ of deaths, respectively) (Chen et al., 2021). A study in the United Kingdom showed that from 2004 to 2014, the proportion of deaths in homes and nursing homes increased ( $18.3 \%$ to $22.9 \%$ and $16.7 \%$ to $21.2 \%$ respectively), while the proportion of deaths in hospital decreased (57.9\% to $48.1 \%$ ) (Bone et al., 2018). A similar trend has occurred in Spain, where death tallies from 2012 to 2015 reveal that two-fold more people are dying in hospitals than at home.

According to the World Health Organization, bone malignant tumors account for $0.2 \%$ of all tumors (Chen et al., 2012a). From 2003 to 2007, Chinese bone cancer mortality rate ranked 19th in the malignant cancer death rates in the country (Chen et al., 2012b). Our previous work has revealed that mortality of bone cancer was $1.12 / 10^{5}$ in Inner Mongolia during the 2008-2012 (Guo et al., 2015). In the same period, the mortality of colon cancer was five-fold than in bone cancer (Xin et al., 2014), and the mortality of breast cancer was nine-fold than in bone cancer (Hu et al., 2014). However, there are few epidemiological studies on bone cancer. Despite the low mortality rate of bone-related diseases, they still have an impact on human life. Therefore, it is necessary to analyze the characteristics of bone-related disease death. 


\section{Materials and Methods}

\subsection{Data Sources}

Death data from 2008 to 2015 were obtained from the Death Registry System at the Inner Mongolia Center for Disease Control and Prevention. These data came from individuals located in the mid-western and eastern regions of monitoring locations in Inner Mongolia. The mid-west monitoring locations included BaMeng Linhe, Baotou Tumd Youqi, Haibowan District, Ejin Horo Qi, Dongsheng District, Huimin District, Chahar Right Front Banner, Alxa Left Banner, Wuchuan County, and the Qingshan District. The eastern monitoring locations included BairinYouqi, Yakeshi City, Kailu County, Sonid Youqi, Keshiketeng Qi, Naiman Banner, Arun Banner, Manzhouli City, Horqin Right Wing Middle, and West Ujimqin Banner. These monitoring locations were selected by the National Disease Monitoring Point System (Yang \& Zheng, 1992; Zhou et al., 2010).

\subsection{Methods}

\subsubsection{Survey Method}

According to the International Classification of Diseases, our study included data on bone-related disease deaths such as those from bone and articular cartilage malignancies (C40) of the limbs (i.e., primary bone cancer) and secondary bone marrow malignant tumors (C79.5) (i.e., secondary bone cancer). Bone diseases such as rickets (M80, M81, M82, M83, M84, M85, M87, M88, M89.9, M90, M91.1, M93.0, and M94.0) were also included. For individuals who expired due to these causes, we classified the site of death as home, medical-related institutions (i.e., medical and health institutions, hospital ward, emergency room, or on the way to the hospital), other, and unknown.

\subsubsection{Statistical Analysis}

We calculated the 8-year average mortality rates from primary bone cancer, secondary bone cancer, and bone disease, broken down by gender, region, and age. The mortality rate was calculated as the number of deaths during the study period/population size $\times 100,000$; age-specific growth rate was calculated as increment/original total $\times 100 \%$. According to the education degree, we also calculated proportion of death sites by region, age, gender, ethnicity, marriage status, and season. Education degree was classified as either high or low, where "high education" included high school and above (high) and "low education" included junior school and below (low). $\chi^{2}$ tests were used to analyze the influence of education degree, demographic characteristics, and season on the distribution of death sites. Microsoft Excel and SPSS25.0 statistical software were used for data analysis and results were considered significant at $P \leq 0.05$.

\section{Results}

The average mortality rate of bone-related disease was $1.59 / 10^{5}$ over the eight-year study period. The mortality of primary bone cancer (64.07\%) was twice that of 
secondary bone cancer (30.95\%), while bone disease only accounted for $4.98 \%$ of bone-related disease mortality. Overall, the mortality rate of male was 1.63 -fold higher than that of female. The mortality rate of primary bone cancer was higher in the eastern regions than in the Midwest by a factor of 1.25:1. Secondary bone cancer and bone disease mortality rates were substantially lower in the east than in the mid-west (0.66:1 and 0.27:1, respectively). Average bone-related disease mortality rate increased with advancing age: while growth rates ranged from $108.19 \%$ to $270.49 \%$ across all results, with the highest growth rate in the 55 -year age group (Table 1).

For the proportion of education degree, the male and female deaths were $63.48 \%$ and $74.85 \%$, respectively in the low education group (Table 2). Male deaths in the low education group were 1.73-fold that in the high education group, while female deaths in the low education group were 2.98 -fold that of females in the high education group. Elderly (age $\geq 55$ ) patients with low education degree were 3.3-fold more likely to die than those in the high education group. The death proportion of low education is higher than that of high education, whether in the eastern or the mid-western regions. In the east, patients with lower education degree were 1.87 -folds more likely to die than those with higher education, while in the midwest, patients with lower education were 2.26 -fold more likely to die than those with higher degree of education.

Table 1. Demographic characteristics of death from bone-related disease in monitoring points of Inner Mongolia Autonomous Region, 2008-2015.

\begin{tabular}{|c|c|c|c|c|c|c|c|c|c|c|c|c|}
\hline & \multicolumn{3}{|c|}{ Total } & \multicolumn{3}{|c|}{ Primary bone cancer } & \multicolumn{3}{|c|}{ Secondary bone cancer } & \multicolumn{3}{|c|}{ Bone disease } \\
\hline & $\mathrm{N}$ & $\begin{array}{c}\text { Mortality } \\
\left(1 / 10^{5}\right)\end{array}$ & $\begin{array}{l}\text { Growth } \\
\text { rate }(\%)\end{array}$ & $\mathrm{N}$ & $\begin{array}{c}\text { Proportion } \\
\text { (\%) }\end{array}$ & $\begin{array}{c}\text { Mortality } \\
\left(1 / 10^{5}\right)\end{array}$ & $\mathrm{N}$ & $\begin{array}{c}\text { Proportion } \\
\text { (\%) }\end{array}$ & $\begin{array}{c}\text { Mortality } \\
\left(1 / 10^{5}\right)\end{array}$ & $\mathrm{N}$ & $\begin{array}{l}\text { Proportion } \\
\text { (\%) }\end{array}$ & $\begin{array}{r}\text { Mortality } \\
\left(1 / 10^{5}\right)\end{array}$ \\
\hline $\begin{array}{c}\text { Average } \\
\text { rate }\end{array}$ & 462 & 1.59 & - & 296 & 64.07 & 1.02 & 143 & 30.95 & 0.49 & 23 & 4.98 & 0.08 \\
\hline \multicolumn{13}{|l|}{ Gender } \\
\hline Male & 295 & 1.95 & - & 193 & 65.42 & 1.27 & 89 & 30.17 & 0.59 & 13 & 4.41 & 0.09 \\
\hline Female & 167 & 1.2 & - & 103 & 61.68 & 0.74 & 54 & 32.34 & 0.39 & 10 & 5.98 & 0.07 \\
\hline \multicolumn{13}{|l|}{ Region } \\
\hline East & 194 & 1.55 & - & 143 & 73.71 & 1.15 & 47 & 24.23 & 0.38 & 4 & 2.06 & 0.03 \\
\hline Midwest & 268 & 1.61 & - & 153 & 57.09 & 0.92 & 96 & 35.82 & 0.58 & 19 & 7.09 & 0.11 \\
\hline \multicolumn{13}{|l|}{ Age } \\
\hline$<25$ & 23 & 0.27 & - & 17 & 73.91 & 0.20 & 5 & 21.74 & 0.06 & 1 & 4.35 & 0.01 \\
\hline $25-$ & 30 & 0.40 & 48.15 & 22 & 73.33 & 0.29 & 6 & 20.00 & 0.08 & 2 & 6.67 & 0.03 \\
\hline $40-$ & 95 & 1.22 & 205.00 & 62 & 65.26 & 0.80 & 31 & 32.63 & 0.40 & 2 & 2.11 & 0.13 \\
\hline 55- & 170 & 4.52 & 270.49 & 106 & 62.35 & 2.82 & 58 & 34.12 & 1.54 & 6 & 3.53 & 0.16 \\
\hline 70- & 127 & 9.41 & 108.19 & 83 & 65.35 & 6.15 & 40 & 31.50 & 2.96 & 4 & 3.15 & 0.03 \\
\hline 85- & 17 & 21.29 & 126.25 & 6 & 35.29 & 7.52 & 3 & 17.65 & 3.76 & 8 & 47.06 & 10.02 \\
\hline
\end{tabular}


Table 2. Distribution of death from bone-related diseases by education degree at monitoring points in Inner Mongolia Autonomous Region from 2008 to 2015.

\begin{tabular}{|c|c|c|c|c|c|c|}
\hline & \multicolumn{2}{|c|}{ Junior school and below } & \multicolumn{2}{|c|}{ High school and above } & \multirow{2}{*}{$\mathrm{X}^{2}$} & \multirow{2}{*}{$\mathrm{P}$} \\
\hline & $\mathrm{N}$ & Proportion (\%) & $\mathrm{N}$ & Proportion (\%) & & \\
\hline Gender & & & & & 6.171 & 0.013 \\
\hline Male & 186 & 63.48 & 107 & 36.52 & & \\
\hline Female & 122 & 74.85 & 41 & 25.15 & & \\
\hline Age & & & & & 36.687 & 0.00 \\
\hline$<55$ & 70 & 48.28 & 75 & 51.72 & & \\
\hline$\geq 55$ & 238 & 76.77 & 72 & 23.23 & & \\
\hline Region & & & & & 0.9 & 0.343 \\
\hline East & 125 & 65.10 & 67 & 34.90 & & \\
\hline Midwest & 183 & 69.32 & 81 & 30.68 & & \\
\hline
\end{tabular}

The highest proportion of the death site in the bone-related death is at home (68.61\%). Of these home-based deaths, primary bone cancer death accounted for $66.89 \%$, while secondary bone cancer death accounted for $73.42 \%$, and bone disease death accounted for $60.87 \%$ by proportion of various death site. The second most common death site was in the hospital ward. In hospital wards, bone-related disease death accounted for $18.40 \%$; of these, primary bone cancer, secondary bone cancer, and bone disease death accounted for $20.27 \%$, 13.99\%, and $21.74 \%$ respectively in proportion of various death site. As such, we classified all death sites as two categories: one is at home, and the other is in medical institutions (Table 3).

Table 4 shows the proportions of the two death sites. In the lower education group, $78.03 \%$ of deaths occurred at home, which was a rate 1.5 -fold higher than in the high education group $\left(P<0.001, \mathrm{X}^{2}=33.988\right)$ (Table 4$)$. In the east, $80.73 \%$ of deaths occurred at home compared to $61.13 \%$ in the mid-west $\left(P<0.001, \mathrm{X}^{2}=\right.$ $20.121)$. Nearly $3 / 4$ of those older than 55 died at home $\left(P<0.05, X^{2}=7.135\right)$. The proportion of death at home by death sites showed that the widower was $77.78 \%$, the married was $69.70 \%$, and the unmarried was $51.52 \%$. Male and females accounted for $68.15 \%$ and $71.52 \%$ of deaths at home, respectively. However, the death site from bone-related disease did not differ between males and females $(P>0.05)$.

The proportion of low education death at home was $76.04 \%$, which was 1.58 -fold higher than that in medical related institutions. The proportion of high education death in medical related institutions was $51.80 \%$, which was 2.13 -fold higher than those that occurred at home. The proportion of low education with secondary bone cancer death at home was $80.58 \%$, which was more than twice as many deaths in medical related institutions. The proportion of high education with secondary bone cancer death in medical related institutions was $61.11 \%$, which was 3.15-fold higher than those that occurred at home (Table 5).

There was no difference between low education and high education in the 
proportion of death sites across the year. The only seasonal differences in death sites occurred in the summer and spring $(P=0.035)$ (Table 6).

Table 3. The distribution of death sites from bone-related diseases at monitoring points in Inner Mongolia Autonomous Region from 2008 to 2015.

\begin{tabular}{|c|c|c|c|c|c|c|c|c|}
\hline \multirow{2}{*}{ Death site } & \multicolumn{2}{|r|}{ Total } & \multicolumn{2}{|c|}{ Primary bone cancer } & \multicolumn{2}{|c|}{ Secondary bone cancer } & \multicolumn{2}{|r|}{ Bone disease } \\
\hline & $\mathrm{N}$ & Proportion (\%) & $\mathrm{N}$ & Proportion (\%) & $\mathrm{N}$ & Proportion (\%) & $\mathrm{N}$ & Proportion (\%) \\
\hline Home & 317 & 68.61 & 198 & 66.89 & 105 & 73.42 & 14 & 60.87 \\
\hline Medical and health institutions & 41 & 8.87 & 24 & 8.11 & 14 & 9.79 & 3 & 13.04 \\
\hline Hospital ward & 85 & 18.40 & 60 & 20.27 & 20 & 13.99 & 5 & 21.74 \\
\hline Emergency room & 10 & 2.17 & 9 & 3.04 & 1 & 0.70 & 0 & 0.00 \\
\hline On the way to the hospital & 4 & 0.87 & 2 & 0.68 & 1 & 0.70 & 1 & 4.35 \\
\hline Other & 3 & 0.65 & 2 & 0.68 & 1 & 0.70 & 0 & 0.00 \\
\hline Unknown & 2 & 0.43 & 1 & 0.33 & 1 & 0.70 & 0 & 0.00 \\
\hline
\end{tabular}

Table 4. Death from bone-related disease sites in demographic characteristics at monitoring points in Inner Mongolia Autonomous Region from 2008 to 2015.

\begin{tabular}{|c|c|c|c|c|c|c|c|c|}
\hline & \multicolumn{2}{|r|}{ Total } & \multicolumn{2}{|c|}{ Medical related institutions } & \multicolumn{2}{|r|}{ Home } & \multirow{2}{*}{$\mathrm{X}^{2}$} & \multirow{2}{*}{$P$} \\
\hline & $\mathrm{N}$ & Proportion (\%) & $\mathrm{N}$ & Proportion (\%) & $\mathrm{N}$ & Proportion (\%) & & \\
\hline Education degree & & & & & & & 33.988 & 0.000 \\
\hline Junior school and below & 305 & 66.74 & 67 & 21.97 & 238 & 78.03 & & \\
\hline High school and above & 147 & 32.17 & 72 & 48.98 & 75 & 51.02 & & \\
\hline Unknown & 5 & 1.09 & 1 & 20.00 & 4 & 80.00 & & \\
\hline Age & & & & & & & 7.135 & 0.008 \\
\hline$<55$ & 146 & 31.95 & 57 & 39.04 & 89 & 60.96 & & \\
\hline$\geq 55$ & 311 & 68.05 & 83 & 26.69 & 228 & 73.31 & & \\
\hline Years & & & & & & & 2.086 & 0.149 \\
\hline $08-11$ & 148 & 32.39 & 52 & 35.14 & 96 & 64.86 & & \\
\hline $12-15$ & 309 & 67.61 & 88 & 28.48 & 221 & 71.52 & & \\
\hline Gender & & & & & & & 0.562 & 0.454 \\
\hline Male & 292 & 63.89 & 93 & 31.85 & 199 & 68.15 & & \\
\hline Female & 165 & 36.11 & 47 & 28.48 & 118 & 71.52 & & \\
\hline Region & & & & & & & 20.121 & $<0.001$ \\
\hline East & 192 & 42.01 & 37 & 19.27 & 155 & 80.73 & & \\
\hline Midwest & 265 & 57.99 & 103 & 38.87 & 162 & 61.13 & & \\
\hline National & & & & & & & 0.298 & 0.889 \\
\hline Han & 406 & 88.84 & 126 & 31.03 & 280 & 68.97 & & \\
\hline Mongolia & 42 & 9.2 & 12 & 28.57 & 30 & 72.43 & & \\
\hline Other & 9 & 1.97 & 2 & 22.22 & 7 & 77.78 & & \\
\hline Marriage & & & & & & & 6.761 & 0.034 \\
\hline Married & 363 & 80.67 & 110 & 30.30 & 253 & 69.70 & & \\
\hline Widowed & 54 & 12.00 & 12 & 22.22 & 42 & 77.78 & & \\
\hline Unmarried & 33 & 7.33 & 16 & 48.48 & 17 & 51.52 & & \\
\hline
\end{tabular}


Table 5. Death from bone-related disease sites by education degree at monitoring points in Inner Mongolia Autonomous Region from 2008 to 2015 .

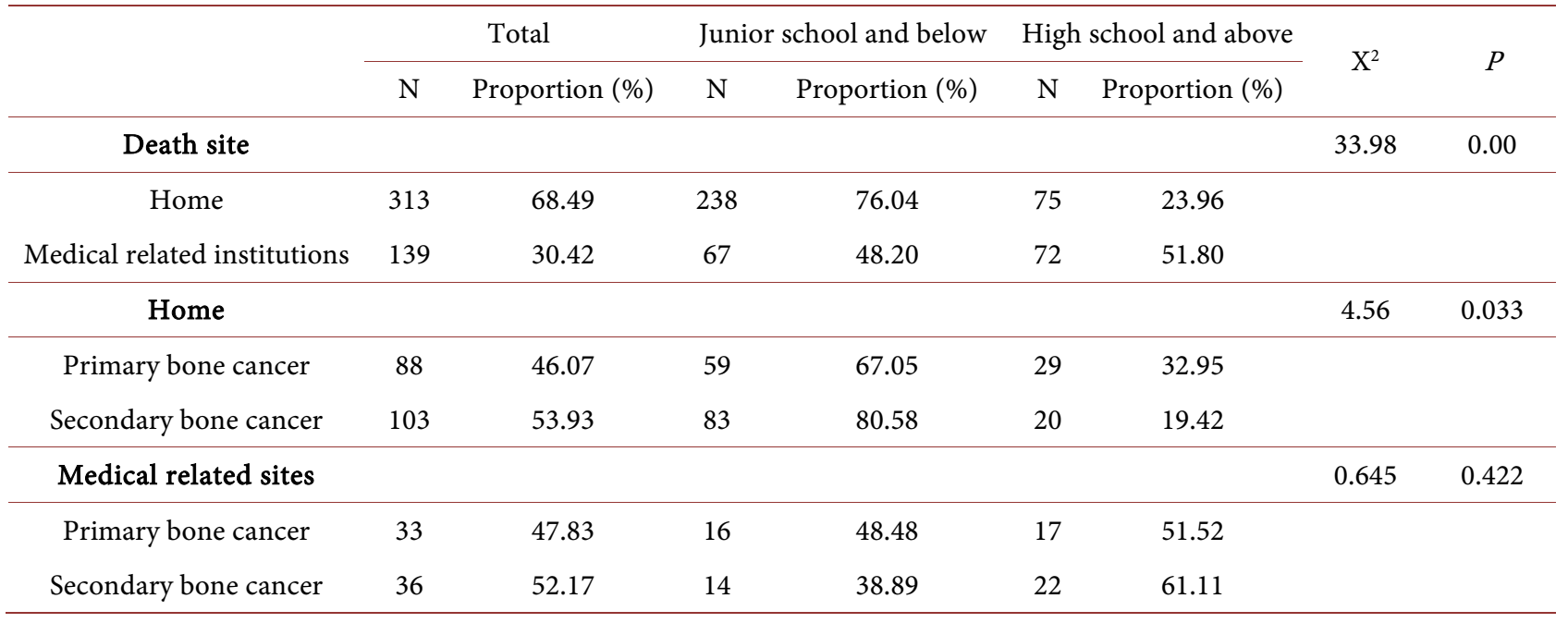

Table 6. Seasonal distribution of death from bone-related diseases sites at monitoring points in Inner Mongolia Autonomous Region from 2008 to 2015.

\begin{tabular}{|c|c|c|c|c|c|c|c|c|c|c|}
\hline & \multicolumn{2}{|r|}{ First quarter } & \multicolumn{2}{|c|}{ Second quarter } & \multicolumn{2}{|c|}{ Third quarter } & \multicolumn{2}{|c|}{ Fourth quarter } & \multirow{2}{*}{$\mathrm{X}^{2}$} & \multirow{2}{*}{$P$} \\
\hline & $\mathrm{N}$ & Proportion (\%) & $\mathrm{N}$ & Proportion (\%) & $\mathrm{N} P$ & oportion (\%) & $\mathrm{N}$ & Proportion (\%) & & \\
\hline Death site & & & & & & & & & 8.586 & 0.035 \\
\hline Home & 72 & 22.71 & 107 & 33.75 & 76 & 23.98 & 62 & 19.56 & & \\
\hline Medical related institutions & 50 & 35.71 & 37 & 26.43 & 30 & 21.43 & 23 & 16.43 & & \\
\hline \multicolumn{11}{|l|}{ Home } \\
\hline Junior school and below & 52 & 21.85 & 80 & 33.61 & 57 & 23.95 & 49 & 20.59 & 1.362 & 0.714 \\
\hline High school and above & 20 & 26.67 & 27 & 36.00 & 15 & 20.00 & 13 & 17.33 & & \\
\hline \multicolumn{11}{|l|}{ Medical related institutions } \\
\hline Junior school and below & 20 & 29.85 & 21 & 31.34 & 15 & 22.39 & 11 & 16.42 & 2.195 & 0.533 \\
\hline High school and above & 29 & 40.28 & 16 & 22.22 & 15 & 20.83 & 12 & 16.67 & & \\
\hline
\end{tabular}

\section{Discussion}

Here, we reveal that the bone-related disease mortality rate in Inner Mongolia $(1.59 / 100,000)$ was slightly higher than that in China $(1.36 / 100,000)$ (Chen et al., $2012 b)$. The mortality rate of primary bone cancer was higher than that of secondary bone cancer. The primary and secondary bone cancers accounted for the majority of all bone-related deaths, exceeding $95 \%$. More than half of bone-related disease deaths occurred at home, with secondary bone cancer deaths occurring at home being higher compared to those from primary bone cancer. The lower the education degree, the higher the proportion of death at home (Li et al., 2012). Our research showed that the proportion of low education degree died at home is high. It is consistent with a study on the death site of Chinese citizens in 2016 (Jing \& Yuan, 2016). Much previous research has investigated the factors 
influencing the death site, including social economic status, education degree, availability of medical services, and traditional beliefs (Han et al., 2015; Li et al., 2012; Jing \& Yuan, 2016). However, a comprehensive study showed that the relationship between the death site and education degree is inconclusive (Neergaard et al., 2019). It is worth noting that the proportion of low education degree of bone-related disease death in elderly exceeded $3 / 4$ and the mortality increased linearly with age, which is consistent with our previous results (Guo et al., 2015). We also found that age had a correlation with death site, and nearly $3 / 4$ of people over 55 years old died at home. Due to the low education degree, as well as the familiar relatives in the environment of home, which can reduce the fear of death (Liao et al., 2019), the elderly prefer to die at home. Marriage status did not influence death site.

We revealed that people with lower degrees of education were more likely to die at home, which is in accord with previously published findings (Li et al., 2012; Jing \& Yuan, 2016). Whether in the mid-western regions or the eastern regions, the death proportion of low education degree is higher than that of high education degree, although there are differences in the death proportion between the eastern and mid-western regions. We also discovered that the proportion of deaths at home was lower in the mid-western region than in the eastern regions. In Inner Mongolia, the western economy is better than that in the East (Tian \& Bao, 2018), which may help explain this pattern (Wang et al., 2020). In both regions, however, more home deaths occurred among those with lower degrees of education. Those who with lower incomes tend to die at home due to high medical expenses and other reasons (Liao et al., 2019; Li et al., 2012). Due to the long and cold winter in Inner Mongolia, the land is sparsely populated, and transportation is inconvenient. As such, we compared the proportion of deaths by both season and education degree. The results showed that the season did not influence the death site.

Our findings showed that deaths from bone-related diseases are mostly at home, which mainly come from bone cancer. Moreover, the lower the education degree, the higher the proportion of deaths at home. This study will be helpful to understand the influence of various demographic characteristics on the distribution of death sites.

\section{Conflicts of Interest}

The authors declare no conflicts of interest regarding the publication of this paper.

\section{References}

Bone, A. E., Gomes, B., Etkind S. N., Verne, J., Murtagh, F. E., Evans, C. J., \& Higginson, I. J. (2018). What is the Impact of Population Ageing on the Future Provision of End-ofLife Care Population-Based Projections of Place of Death. Palliative Medicine, 32, 329-336. https://doi.org/10.1177/0269216317734435

Cabaero-Martínez, M. J., Nolasco, A., Melchor, I., Fernández-Alcántara, M., \& Cabrero- 
García, J. (2019). Place of Death and Associated Factors: A Population-Based Study Using Death Certificate Data. European Journal of Public Health, 29, 608-615. https://doi.org/10.1093/eurpub/cky267

China Disease Control and Health Publish (2005). The National Disease Surveillance System's Work Standards for the Monitoring of Death Causes (Trial).

Chen, L. L., Zhang, Y. X., Wang, J. Y., Zhao, J., Jiang, N., Wang, J. W., Xu, H. L., Liu, X. H., Yu, J. M., \& Jiang, Q. W. (2021). Analysis of Mortality Surveillance of Residents in Minhang District of Shanghai from January to April in 2016-2020. Shanghai Journal of Preventive Medicine, 4, 335-339.

Chen, Z. F., Chen, W. Q., Chen, J. G., Wang, N., Zheng, Y., Song G. H., \& Liu, Z. C. (2012a). Bone Analysis of Cancer Incidence in Population-Based Cancer Registration in China. Chinese Journal of Clinical Oncology, 20, 1509-1513.

Chen, Z. F., Chen, W. Q., Chen, J. G., Wang, N., Zheng, Y., Song, G. H., \& Liu, Z. C. (2012b). An Analysis of Mortality of Bone Cancer in China, 2003-2007. China Cancer, 8, 566569.

Guowei Planning Publish (2013). Notice on Further Regulating the Management of Population Death Medical Certificates and Information Registration.

Guo, W. F., Hao, W. L., Du, M. L., Su, Z., Hu, Y. L., Xia, Y., Su, X., \& Sun, J. (2015). Bone Cancer Mortality in Inner Mongolia from 2008 to 2012. Open Journal of Epidemiology, 5, 59-64. https://doi.org/10.4236/ojepi.2015.51008

Han, X., Zhou Y., Wang, L. J., \& He, Y. (2015). Factors Influencing the Place of Death in Beijing Dongcheng South District Patients with Cancer, 2007-2012. Journal of Medical Research, 5, 57-60.

Hu, Y. L., Li, Y., Wang, W. R., Qian, Y. G., Hui, C. X., Xin, K. P., Wang, S. Q., \& Sun, J. (2014). The Characteristics of Breast Cancer Mortality in Inner Mongolia between 2008 and 2010. Open Journal of Epidemiology, 4, 135-140.

https://doi.org/10.4236/ojepi.2014.43019

Jiang, S. Y., Wu, B., \& Yu, X. S. (2020). Analysis of Death Places of Cerebrovascular Diseases among Urban and Rural Residents in China. Chinese Journal of Health Statistics, 3, 448-451.

Jing, J., \& Yuan, Z. Y. (2016). Died in Hospital and at Home-Sociological Analysis of the Chinese Citizen's Place of Death. Thinking, 2, 14-18.

Li, L., Liu, Q. M., \& Jin, D. F. (2012). A Study on Distribution of Death Location and Influencing Factors among Hangzhou Residents. Preventive Medicine, 2, 17-19.

Liao, J., Mao, J., Chen, F. J., Wen, Q., Zhou, W., \& Ni, P. (2019). Preferences for Place of Death and the Predictions among Patients with Advanced Malignant Cancer. Journal of Nursing Science, 15, 78-81.

Neergaard, M. A., Brunoe, A. H., Skorstengaard, M. H., \& Nielsen, M. K. (2019). What Socio-Economic Factors Determine Place of Death for People with Life-Limiting Illness? A Systematic Review and Appraisal of Methodological Rigour. Palliative Medicine, 33, 900-925. https://doi.org/10.1177/0269216319847089

Tian, F., \& Bao, Y. D. R. (2018). Regional Economic Disparity between the East and The West in Inner Mongolia: Internal Causes and Dynamic Changes. Journal of Inner Mongolia Agricultural University (Social Science Edition), 20, 31-39.

Wang, Y., Jia, R., \& Chen, N. (2020). Study on the Construction and Measurement of the Evaluation System of Inner Mongolia's Economic High-Quality Development. Journal of Inner Mongolia University (Natural Science Edition), 4, 441-444.

Xin, K. P., Du, M. L., Liu, Z. Y., Wang, W. R., Qian, Y. G., Liu, L., \& Sun, J. (2014). Colorectal Cancer Mortality in Inner Mongolia between 2008 and 2012. World Journal of 
Gastroenterology, 20, 8209-8214. https://doi.org/10.3748/wjg.v20.i25.8209

Yang, G. H., \& Zheng, X. W. (1992). The Second Phase of Disease Surveillance Point Selection and Representation. Chinese Journal of Epidemiology, 4, 197-201.

Zhou, M. G., Jiang, Y., Huang, Z. J., \&Wu, F. (2010). Adjustment and Representativeness Evaluation of National Disease Surveillance Point System. Disease Surveillance, 3, 239-244. 